\title{
Construção de identidades femininas: as narrativas sobre a Seleção Brasileira Feminina de Futebol no "Globo Esporte" e "Esporte Espetacular"
}

Recibido: 30 de julio de 2018

Aceptado: 3 de octubre de 2018

Publicado: 28 de noviembre de 2018
Isadora Nascimento isadora.npsousa@gmail.com

Gustavo Said

gsaid@uol.com

Universidade Federal do Piauí (Brasil)

Resumen: Esta investigación analiza la construcción de las identidades femeninas en las noticias acerca de la Selección Brasileña de Fútbol Femenino, transmitidas en los programas "Globo Esporte" y "Esporte Espetacular" de la Rede Globo de televisión durante los Juegos Olímpicos de 2016. Se destacan las discusiones sobre identidad realizadas por Hall (2016), Woodward (2000) y Bhabha (1998); conceptos de representaciones sociales de Moscovici (2015); de género, como la planteada por Scott (1995) y de estereotipos realizada por Hall (2016), Bhabha (1998) y Moscovici (2015); así como en torno a la influencia de los medios en la sociedad contemporánea de Birolli (2011). A partir de un análisis de contenido, según el concepto de Bardin (2011), se constató que, a diferencia de lo que se esperaba, hubo la creación y diversificación de los modelos identitarios reproducidos mediáticamente, huyendo de las imágenes estereotipadas relacionadas a la identidad femenina.

Palabras clave: Identidad, mujer, fútbol, representaciones, estereotipos, periodismo deportivo.

Abstract: This research addresses the analysis of the construction of the female identity in the news regarding the Female Brazilian National Soccer Team broadcasted in "Globo Esporte" and "Esporte Espectacular", from Rede Globo de Televisão, during the 2016 
Olympic Games. The identity discussions of Hall (2016), Woodward (2000) and Bhabha (1998); concepts of social representation by Moscovici (2015); the discussion of gender by Scott (1995) and stereotypes of Hall (2016), Bhabha (1998) and Moscovici (2015); as well as discussions regarding the influence of media in contemporary society by Birolli (2011) are highlighted. From the analysis of content by Bardin (2011), contrary to what was expected, there was a creation and diversification of identity models propagated through media, avoiding stereotypical images related to the female identity.

Key words: Identity, Woman, Soccer, Representations, Stereotypes, Sports Journalism.

\section{Introdução}

Mundo afora, o Brasil possui a fama de país de futebol. Essa realidade de se configurar como uma "pátria de chuteiras", propagadora do futebol-arte, entretanto, parece ser condizente apenas com o âmbito masculino. São visíveis as enormes discrepâncias entre o futebol masculino, que movimenta altos valores financeiros, cria ídolos e produz grandes estrelas do esporte mundial, e o feminino, que luta para sobreviver a duras penas, com poucos incentivos privados e políticas públicas e praticamente relegado ao amadorismo.

Medidas proibitivas quando o futebol começou a se consolidar com a representatividade que possui hoje para a cultura brasileira adiaram a legalização e profissionalização da prática futebolística para mulheres. Além da difusão e reforço de convenções normativas por meio dos instrumentos de controle social, como a mídia, no que concerne à concepção de um ideário de modelos de feminilidade. Assim, a mídia se reveste de um papel fundamental na produção de significados e de representações, que facilitam o entendimento de mundo e funcionam como pontos de identificação.

Portanto, o objetivo desta pesquisa é analisar como a identidade feminina é construída (e que identidade é essa) nas notícias sobre a seleção brasileira de futebol feminino veiculadas no "Globo Esporte" e "Esporte Espetacular", principais noticiários esportivos da Rede Globo, durante as Olimpíadas de 2016, realizadas no Rio de Janeiro.

A justificativa para realização desta fundamenta-se na necessidade de inferir e compreender de que forma a mídia, especificamente o jornalismo esportivo, influencia na construção de pontos de identificação para os sujeitos sociais, bem como demonstrar a relevância jornalística na criação, reforço ou rompimento das barreiras de condutas sociais, verificando qual o comportamento adotado frente à sociedade estigmatizada e à identidade feminina estereotipada.

Para concretizar os objetivos desta pesquisa, o trabalho inicia as reflexões acerca das possibilidades de compreensão sobre as identidades sociais, com base em Bhabha (1998) e Hall (2000, 2016). A próxima parte, por sua vez, discute as questões de gênero no estabelecimento da identidade feminina e na naturalização de estereótipos a ela associados 
por meio das representações sociais utilizando Scott (1995) e Moscovici (2015) como referência. Em seguida, busca-se evidenciar a contribuição da mídia para o reforço e manutenção dos estereótipos construídos sobre as mulheres, especialmente as que praticavam esporte o futebol, especificamente.

Por fim, o artigo traz a análise do corpus desta pesquisa, que é constituído de 17 inserções coletadas entre os dias 05 de julho de 2016 e 21 de agosto de 2016 nos programas "Globo Esporte" e "Esporte Espetacular". Esta etapa usa como método a análise de conteúdo categorial segundo o conceito de Bardin (2011).

\section{Identidades: a alteridade como ponto de partida}

Etimologicamente, a palavra "identidade", em sua significação gramatical mais simplória e originária do latim identitas (isto é, idem, mesmo, idêntico), estaria relacionada ao conjunto de características de um indivíduo ou grupo que os diferenciem dos demais. Assim, o ponto de partida para o estabelecimento e a construção ou remodelação de identidades é o próximo, é o Outro, e as relações com ele estabelecidas nos mais diversos âmbitos constituintes da sociedade, seja familiar, laboral, político, social, nacional.

Pollak (1992) argumenta que "Ninguém pode construir uma autoimagem isenta de mudança, de negociação, de transformação em função dos outros” (p. 204). E o indivíduo existe enquanto corpo material, entretanto "existir é ser chamado à existência em relação a uma alteridade, seu olhar ou lócus. É uma demanda que se estende em direção a um objeto externo" (Bhabha, 1998, p. 76).

O Outro é o responsável direto por marcar, demarcar, delimitar a(s) diferença(s) entre umas identidades e outras. No entanto, o estabelecimento ou identificação de uma diferença, naturalmente, conduz a um caminho de negação e, posterior, exclusão. Trazendo à luz a situação mulher x homem, para além das discussões acercas de determinações biológicas. Se eu sou mulher é porque eu não posso e não sou homem. Há um pressuposto de que não pode, não deve e não existe qualquer similaridade.

Assim, a consequência imediata é que a diferença e, por sua vez, as identidades são caracterizadas como dicotomias diametralmente opostas, maniqueístas. A referida determinação reduz as identidades a significados e representações em forma de binarismo ou oposições binárias: a mulher está associada imediatamente à emoção, ao simbolismo do coração, enquanto o homem, seu oposto, é a representação da razão, do cérebro.

Por outro lado, a diferença também pode ser celebrada como fonte de diversidade, heterogeneidade e hibridismo, sendo vista como enriquecedora. Porém, a posição adotada, em sua maioria e essência, é a negativa, que, pressupõe o maniqueísmo e, por consequente, determina uma relação tendenciosa de desequilíbrio de poder entre as identidades ditas opostas (Derrida, citado por Hall, 2016). 
Com base em supostas indicações biológicas, o homem é identificado como hegemônico em relação ao seu suposto oposto: a mulher. Ainda que a diferença inicialmente considerada para distinguir o sexo feminino do masculino não seja oposta, ela é continuamente usada para justificar e explicar as posições sociais que cada uma dessas identidades ocupam e/ou devem ocupar. A mulher, sempre relacionada à natureza, a aspectos instintivos, fraqueza, emoção, e o homem, à cultura, racionalidade, força.

Hall (2016) argumenta, entretanto, que "a diferença é 'ambivalente"” (p. 160). Ao passo que exclui, reduz, simplifica, negativa o Outro no processo de construção de identidades, ela também contribui para a identificação do ser enquanto sujeito social.

Quando a diferença é estabelecida somente como marcadora de oposições binárias, esta remete à perspectiva essencialista para a determinação de identidades. O essencialismo firma a identidade como fixa, imóvel, inata, resistente à passagem do tempo, à história, relacionada ao determinismo biológico e ao passado "imaginado". Assim, os sujeitos seriam pré-estabelecidos, pré-determinados, sem possibilidades de alterações.

Em contrapartida, o construcionismo (ou não-essencialismo), afirma a existência de identidades plurais, fluídas, em permanente e constante construção, remodelação ou reafirmação. Sob essa linha de raciocínio, as identidades são um processo constante, que resultam das experiências culturais, históricas, de vida por meio do compartilhamento com o Outro, do convívio social com a(s) diferença(s). Se o Outro e as relações sociais com ele estabelecidas estão sempre se modificando, o resultado disto são identidades fluídas, flexíveis.

A fluidez que caracteriza e permeia as sociedades pós-modernas é resultado, argumenta Woodward (2000), das profundas mudanças sociais que se iniciaram com o processo de globalização. Não há mais somente um centro que emane e determine estilos de vida e cultura. Dessa forma, há uma infinidade de lugares e possibilidades das quais podem surgir novas identidades, plurais.

A sociedade pós-moderna possui uma grande quantidade de âmbitos sociais e, em cada um deles

[...] podemos nos sentir, literalmente, como sendo a mesma pessoa, mas nós somos, na verdade, diferentemente posicionados pelas diferentes expectativas e restrições sociais envolvidas em cada uma dessas diferentes situações, representando-nos, diante dos outros, de forma diferente em cada um desses contextos. Em um certo sentido, somos posicionados -e também 'posicionamos a nós mesmos- de acordo com os "campos sociais" nos quais estamos atuando (Woodward, 2000, p. 30).

Ao assumir essas diferentes, plurais e fluídas identidades, além de reconhecer a não existência de uma identidade fixa, o indivíduo constantemente se vê em um conflito e crise relacionado ao processo de identificação. O papel de mãe, por exemplo, pressupõe máxima atenção, cuidado e zelo, mas como o fazer se a mulher dita moderna tem uma série de outras atribuições (como trabalhar fora de casa) conquista que foi reivindicada durante décadas? 
Além das questões internas, outro conflito surge exatamente das normas e convenções sociais estabelecidas para cada uma das identidades e que podem ir de encontro. A identidade feminina remete à feminilidade, delicadeza, maternidade, heterossexualidade. Uma mulher que é atleta de futebol feminino não corresponde às expectativas e limitações sociais.

A identidade seria, pois, um processo constante de interação social com o Outro e o mundo exterior, por meio da qual o indivíduo se constrói e se constitui enquanto sujeito social, se enxerga como parte ativa de um coletivo, se identifica com o comum pelo qual se sente representado. É nesse contexto em que se estabelecem as representações, que, além de se constituírem como elementos que facilitam a compreensão do mundo, funcionam como pontos de identificação para os indivíduos.

\section{As representações sociais, a estereotipagem e o gênero}

Há usos corriqueiros e socialmente imperceptíveis e legitimados na linguagem de expressões como "lista negra", "a situação está preta", "mercado negro", "magia negra", "câmbio negro", "peste negra", "buraco negro", "humor negro", "passado negro", entre outros. Em todas essas e muitas outras situações do cotidiano, o sentido atribuído às palavras é pejorativo, fruto da construção social em torno da figura do negro africano escravizado no Brasil. Ainda que o significado primeiro de negro e preto no dicionário seja referente à coloração e ao indivíduo que a possui, elas assim foram significadas e legitimadas no imaginário social do brasileiro.

A referida situação é uma tentativa de expressar, simploriamente, o que, como e quais as consequências mais diretas de um processo de representar socialmente algo, alguém, uma ideia, uma palavra, um gesto, um material físico, tudo que se constitui e ultrapassa a barreira do natural. Então, as representações sociais "produzem a mesma experiência que o mundo natural produziria” (Bower, citado por Moscovici, 2015, p. 32).

Moscovici (2015) compreende a representação social como um fenômeno dinâmico, móvel, circulante, fluído. A compreensão se relaciona com a estrutura interna dessas representações, que estão inseridas em um contexto social de interação, cujas relações, comportamentos, normas, códigos, convenções se modificam de acordo com o momento, com a conjuntura histórica

O conceito e o próprio termo gramatical "gênero" surgiu e foi se modificando atendendo ao contexto e, principalmente, às lutas feministas. Carvalho (2011) aponta que a origem da palavra é inglesa e era usada estritamente para diferenciar gramaticalmente palavras femininas de masculinas ou neutras. Em outro momento, passa a ser sinônimo de mulher. E é somente no século XXI que o gênero passa a abranger a configuração e implicação das relações sociais e sexuais (Scott, 1995).

A partir de então, o gênero passa a ser tratado como um signo representativo já que também é resultado de um processo de construção histórica e social e que significa as relações sociais, 
sexuais e de poder frente às diferenças biológicas. Ou como explicita Scott, citada por Nicholson (1999), "o gênero é o conhecimento que estabelece significados para as diferenças corporais. [...] e não pode ser isolado de sua implicação num amplo espectro de contextos discursivos" (p. 2).

Hall (2016) apresenta a representação como um processo de produção de sentido pela linguagem. Representar seria uma forma de tornar o mundo e todas as coisas materiais e abstratas que nele existem inteligíveis, compreensíveis e, assim, permitir e facilitar a comunicação entre os indivíduos, grupos sociais, sociedades e culturas.

A significação das coisas em um processo de construção de sentidos remete à perspectiva construtivista apontada por Hall (2016) para explicar como a representação se sedimenta. Segundo o autor, as coisas, os símbolos, os gestos, as imagens, as ideias não possuem significado por si próprias, apenas no mundo das representações, dos simbolismos. Elas existem, mas essa existência somente é reconhecida com a função que adquirem quando inseridas em sociedade "porque um som ou palavra em particular indica, simboliza ou representa um conceito, ele pode funcionar na linguagem, como um signo e transportar sentido -ou, como os construtivistas dizem, significar" (Hall, 2016, p. 49).

Woodward (2000), explica que é a partir dos significados que se dão às práticas sociais que a interação, a experiência em sociedade e a forma como cada indivíduo se projeta adquirem sentido e razão de ser e existir. Assim, as representações e o processo de significar só acontecem mediante a existência de um código, que sedimenta o sentido atribuído à experiência social (Hall, 2000). O código funciona como um sistema representacional que liga o objeto, o gesto, a imagem, a ideia ao conceito, isto é, relaciona o significante ao significado. Ele é dependente da cultura e das convenções, comportamentos e normas sociais que existe em cada uma delas.

Moscovici (2015) trata a representação como uma forma de encaixar, de explicar, de enquadrar, de facilitar o entendimento acerca de tudo o que é estranho, desconhecido ou novo. Por isso, as representações sociais classificam, categorizam, organizam o mundo em modelos pré-determinados, familiares, conhecidos porque o não familiar incomoda, causa medo e angústia. Dessa forma, as representações convencionalizam os gestos, as ideias, as imagens, os objetos, as pessoas, tudo o que é de caráter social, em paradigmas existentes "através das quais nós podemos distinguir se um braço é levantado para chamar a atenção, para saudar um amigo ou para mostrar impaciência” (Moscovici, 2015, p. 34).

E é nesse processo de classificação que o estereótipo se sedimenta e se instaura como um ponto de interpretação e compreensão do mundo e de tudo o que nele existe ao indivíduo. Como fruto das práticas representacionais, os estereótipos são usados na manutenção do status quo e na tentativa de normatizar e enquadrar tudo o que é novo, estranho aos padrões sociais aceitáveis na sociedade (Hall, 2016). Desse modo, ele atua preferencialmente em classes minoritárias e mais suscetíveis a movimentos de opressão e sanções sociais.

De modo semelhante, o gênero também imprime implicações no poder que permeia as interações (Scott, 1995). As mulheres foram e são encravadas em uma infinidade de 
modelos e normatizações sociais que determinam a sua conduta e atuação no ambiente social até mesmo desde antes do nascimento. Criou-se uma ideia de feminilidade, com uma série de regras sociais, atributos físicos, características psicológicas e estereótipos, como uma cartilha de bons modos que deve ser seguida à risca sob a ameaça de exclusão caso não se corresponda às expectativas sociais.

Assim, além de negar a existência de qualquer diversidade por meio do engessamento e congelamento das representações sociais, os estereótipos relegam grupos sociais subjugados a ocuparem posições de desnível social com base em julgamentos que utilizam as representações e determinam o que é “o 'normal' e o 'patológico', o 'aceitável' e o 'inaceitável', o 'pertencente' e 'o que não pertence', 'pessoas de dentro' (insiders) e 'pessoas de fora' (outsiders), 'nós' e 'eles"' (Hall, 2016, p. 192). Esses mesmos estereótipos estabelecidos nas questões de gênero que associam, até hoje, as mulheres a uma inferioridade biológica, física e cognitiva e as colocam em lugares de opressão, exploração e de dominação.

Moscovici (2015) argumenta que o produto dessa classificação pode ser qualquer um, mas é o código que o determina assim uma vez que haja uma ideia geral e comum, a relação que se estabelece entre o objeto, o gesto, a imagem e o significado se torna uma prática social compartilhada e necessária para todo o grupo social, isto é, uma representação social. Em um pensamento compartilhado, Hall (2016) e Moscovici (2015) apontam as representações sociais como um local de identificação, em que há uma necessidade latente de conferir identidades sociais ao desconhecido, ao estranho.

Birolli (2011) explicita que os estereótipos contribuem para o processo de identificação de grupos por outros indivíduos, grupos, sociedades, mesmo que esses grupos sociais não os aceitem como categorias de representação. E, ainda segundo a autora, "os meios de comunicação têm, nas sociedades contemporâneas, um papel central na difusão de representações do mundo social" (p. 85). Assim, um dos sistemas que cria, reproduz, sedimenta e legitima essas representações e, consequentemente, os estereótipos como realidades inquestionáveis é a mídia.

\section{A identidade feminina na mídia}

Nas sociedades contemporâneas e em um movimento que teve o início mais enfático na modernidade, a mídia está intrinsecamente associada ao cotidiano e à vida social dos indivíduos. Os produtos midiáticos, desde as inúmeras formas de publicidade, as novelas, os noticiários, os seriados, além das diversas plataformas onde estes podem ser difundidos e acessados, são tão parte constituinte da sociedade, que se torna árduo identificar o que influencia o quê e como esse processo se firma.

Em um processo semelhante e simultâneo à globalização, o desenvolvimento tecnológico dos aparatos técnicos midiáticos, isto é, dos suportes para os meios de comunicação de massa modificaram e continuam modificando profundamente a conjuntura social no que tange, principalmente, ao estabelecimento das relações e interações. 
Os meios de comunicação de massa, ao criarem, ressignificarem, difundirem e propagarem representações, criam e legitimam modelos e/ou padrões de identidades, com os quais os sujeitos podem se identificar, reforçar ou rejeitar. Nesse processo de selecionar assuntos, eleger modelos representacionais e escolher o modo como estes serão difundidos (Bastos \& Ristum, 2003), a mídia pode atuar na manutenção, reforço ou ruptura dos padrões sociais.

Nessas sociedades contemporâneas, a relação entre os indivíduos e os meios de comunicação é de dependência cognitiva (Birolli, 2011). Os sujeitos usam os padrões e as representações sociais propagadas pela mídia como ponto de referência para identificação e é devido a isso que os processos de comunicação são "'fenômenos de produção de identidade, de reconstituição de sujeitos, de atores sociais' [...] e os meios de comunicação são um fenômeno cultural através do qual a pessoa, ou muitas pessoas, cada vez mais pessoas vivem a constituição do sentido de sua vida" (Martin-Barbero, citado por Escosteguy, 2001, p. 165).

Assim, os meios de comunicação, como intermediadores de relações sociais entre os indivíduos e entre o sujeito social e o mundo em que está inserido, se constituem como produtores e propagadores das representações, as quais podem ser aceitas ou rejeitadas como pontos de identificação e, portanto, de identidades sociais.

O processo de imposição de comportamentos e concepções normativas à identidade feminina foi maciçamente reforçado no ambiente midiático em torno da reversão de valores e evoluções sob o ideário de feminilidade que se construiu ao longo da história. Ainda que tenham conquistado mais espaço e mais direitos antes exclusivos à ala masculina, as representações das mulheres na mídia no início do século XX passam a adquirir contornos de objetificação, reduzindo-a a um corpo e suas características físicas (Boris \& Cesídio, 2007).

Em um movimento que ora trata a figura feminina como simples objeto (de desejo para os homens) ora como sujeito (Castro \& Prado, 2004) ao propagar e difundir modelos de feminilidade (que hoje se centram na ideia de supermulheres, mulheres modernas, que conseguem conciliar todas as exigências sociais), o discurso midiático sobre a mulher é pautado e pauta sob a influência do imaginário social que se criou acerca da feminilidade.

No jornalismo esportivo (ambiente em que o acesso feminino foi praticamente proibido durante muito tempo, especialmente nas práticas esportivas consideradas mais agressivas e, portanto, exclusivamente masculinas, como as lutas e o futebol), as narrativas criadas e reproduzidas não foram e não são distantes do que se difunde em outros âmbitos sociais. Apesar do discurso se modificar com o passar dos anos e de acordo com a evolução da inserção das mulheres nos desportos, o enfoque é, em sua maioria, direcionado a questões relacionadas a essa imagem de mulher tão aclamada pela sociedade.

No que diz respeito ao futebol feminino, os conteúdos noticiosos, como afirma Goellner (2005a), questionavam exaustivamente a capacidade, habilidade e destreza das mulheres, com constantes "pontos de interrogação" acerca da feminilidade destas atletas. Após a 
oficialização da prática futebolística, ao invés de se ater às questões técnicas do esporte, o jornalismo transfere o foco para os corpos femininos e, consequentemente, sua erotização. Desse modo, submetendo as mulheres ao reforço dos padrões normativos para a concepção do que é ser feminino, associado à estética, comportamentos delicados e discretos, ocupação de locais sociais inferiores aos do homem.

Ainda que houvesse algumas poucas tentativas de romper a barreira da propagação desses estereótipos e dessas normatizações sociais que foram impostas às mulheres (Mourão \& Morel, 2005), o jornalismo esportivo ainda se centra em exaltar a feminilização, enfatizando questões triviais para o futebol feminino em si, mas que corroboram e colaboram com a manutenção da ordem social da imagem da mulher construída socialmente.

\section{Procedimentos metodológicos}

Esta pesquisa será conduzida fundamentalmente por meio da análise de conteúdo que, segundo a conceituação de Bardin, é "um conjunto de técnicas de análise das comunicações visando obter por procedimentos sistemáticos e objetivos de descrição do conteúdo das mensagens indicadores (quantitativos ou não) que permitam a inferência de conhecimentos" (Bardin, 2011, p. 48). A fim de satisfazer o seu objetivo principal, foi escolhida a abordagem categorial.

Posto isso, a referida pesquisa aconteceu em três fases principais. Na primeira delas, o material de análise foi coletado. Obedecendo ao período demarcado para o corpus, todas as edições dos programas "Globo Esporte" e "Esporte Espetacular" transmitidas entre 5 de julho de 2016 e 21 de setembro de 2016 e hospedadas no Globo Play foram assistidas a fim de se realizar uma seleção de todo o material referente ou que mencionassem a Seleção Feminina de Futebol. O resultado final foram 17 inserções encontradas em 79 programas ("Globo Esporte": 68; "Esporte Espetacular": 11).

Na segunda fase, cada uma das matérias que formam o corpus foi analisada, interpretada, quantificada e distribuída em categorias. Essa categorização aconteceu com o objetivo de se verificar e determinar os temas mais predominantes com base na frequência com que eles aparecem. Nesse momento, cada matéria foi dividida segundo unidades de análise, que, nesse caso, corresponderam a cada off, sonora e/ou passagem que compunham cada inserção.

Assim, as categorias encontradas (em ordem decrescente quanto ao critério da frequência) foram: "Busca pelo ouro inédito" (em números brutos, 31 vezes); "Marta: a consolidação de um ídolo" (23 vezes); "Nova geração x craques do passado: renovação e desconhecimento" (20 vezes); "A paixão de uma torcida" (19 vezes); "Natureza feminina: a alteridade do masculino" (18 vezes) e "Show de futebol" (17 vezes).

Por fim, todos os resultados foram analisados e interpretados à luz da discussão teórica proposta na referida pesquisa, observando a identidade feminina e as nuances de sua construção nas notícias dos programas analisados. 


\subsection{Busca pelo ouro inédito}

A cada quatro anos, milhares de atletas de quase todas as nações do mundo se reúnem em alguma cidade para disputarem e competirem entre si em um conjunto de modalidades esportivas. Esses são os Jogos Olímpicos de Verão, que se constituem, hoje, como um megaevento. O maior, mais televisionado, mais assistido (considerando a audiência de todos os dias de competição) evento esportivo do mundo se configura como um verdadeiro fenômeno de marketing (Proni, 2009).

Por outro lado, os atletas buscam se estabelecer em uma curva crescente. Seja para ter a chance de participar de uma edição dos Jogos, tornando esse o grande objetivo (ou sonho) da sua vida esportiva. Seja para melhorar cada vez mais os resultados, quebrar os próprios recordes, ultrapassar os próprios limites e se transformar em verdadeiras lendas do esporte mundial.

Rubio (2010) também aponta um dos fatores que levaram à profissionalização do esporte como um todo e elevaram os Jogos Olímpicos ao patamar de megaevento. Em época de Guerra Fria, as competições olímpicas se constituem como um campo ideal para a disputa entre os países dos blocos socialista e capitalista, em que os melhores resultados, isto é, as medalhas de ouro, eram o que interessava.

A busca incessante pela medalha de ouro (indo de encontro a toda filosofia olímpica pregada pelos gregos e por Coubertin) transforma os atletas em profissionais, com treinos exaustivos, desenvolvimento de técnicas de aprimoramento, investimentos absurdos.

Desta forma, a categoria "Busca pelo ouro inédito" enquadra todas as unidades de análise que remetam ao caminho construído e adotado pela Seleção Feminina para a conquista do objetivo maior: a inédita medalha de ouro. Nessas unidades, fica evidente o discurso produzido e reproduzido maciçamente pela mídia de que o único resultado que importaria seria o primeiro lugar, especialmente porque em outras edições dos Jogos havia se chegado tão perto do lugar mais alto do pódio. Assim, a população e torcida brasileira, já contagiada pelo espírito olímpico e pela empolgação de sediar um evento dessa proporção, também adotaria esse sentimento de expectativa e ansiedade em torno da busca por mais um título para o futebol brasileiro.

Os momentos das matérias englobados nesta categoria ressaltam e exaltam a intensa e diferenciada preparação das "nossas meninas" (termo constantemente usado pela apresentadora do "Globo Esporte", Fernanda Gentil, para se referir às jogadoras) para jogar uma Olimpíada em casa. Por vezes, o conteúdo passa a impressão e sensação de que o ouro é certo e a única possibilidade aceitável. Quando o caminho imaginado esbarra na equipe sueca (detentora de uma tradição maior no futebol feminino) nas semifinais, o espaço dedicado ao time brasileiro é drasticamente reduzido. Apesar de não se adotar uma postura de fracasso e frustração explícita, os programas a relegam a um plano inferior na sua programação.

Em um movimento totalmente contrário ao que acontecia nos primórdios da conquista do direito à participação feminina nos esportes, o que se evidencia é a capacidade competitiva 
das mulheres, submetendo-as às pressões e discursos vitoriosos, cuja vitória é a única saída. Nesse caso específico, criou-se uma onda de expectativa maior ao se ressaltar insistentemente como estava acontecendo a preparação para participar e (implicitamente, ganhar) os Jogos Olímpicos na frente da torcida brasileira, além do uso constante da expressão "ouro inédito".

No início do processo de inserção feminina, o esporte se restringiria a desenvolver e preparar o corpo para uma maternidade sadia, funcionando como um ambiente de reforço dos estereótipos de feminilidade, que colocam a maternidade como um aspecto natural, invariável, inquestionável e sublime do que é ser mulher. Ao contrário disso, o que se observa no teor das matérias sobre a preparação e participação da seleção feminina nos Jogos Olímpicos 2016 é um discurso que preza por uma competitividade e totais condições de vitória ao final da Rio 2016, colocando a equipe brasileira de futebol em um patamar diferenciado e naturalizando a identidade de mulheres atletas, que fazem do esporte a sua profissão.

Logo na primeira inserção registrada no período delimitado para coleta do material, uma nota coberta intitulada "Vedão convoca os 18 nomes para seleção feminina de futebol na Olimpíada" ("Globo Esporte", 13/VII/2016), a apresentadora Fernanda Gentil, ao destacar os principais nomes convocados, já utiliza a frase que nomeia essa categoria: "Busca pelo ouro inédito". As atletas convocadas ficam em segundo plano para se destacar o objetivo maior de uma participação olímpica: a medalha de ouro.

Em outra matéria, com o título "Seleção Feminina de futebol vai estrear antes mesmo da festa de abertura da Rio 2016" ("Esporte Espetacular", 31/VII/2016), a repórter Maíra Lemos $^{1}$, intercalando imagens dos treinos com o texto, destaca o esforço e a dedicação nessa fase preparatória, passando uma sensação de segurança e tranquilidade ao telespectador ansioso para a estreia no que se refere às táticas de treinamento. É uma mensagem com o teor de que a equipe está pronta e bem armada para os confrontos que virão.

Essa incessante referência aos treinos, às táticas de preparação, ao foco, à luta, ao esforço diferenciado é reforçado em boa parte das matérias. Em uma entrada ao vivo, "Cristiane fala sobre a expectativa da seleção feminina para os Jogos Olímpicos" ("Globo Esporte", 26/VII/2016), direto da Vila Olímpica, a maior artilheira olímpica e um dos grandes nomes da história da seleção ressalta que o mesmo grupo está treinando há dois anos, o que ajuda a criar uma intimidade e estilo de jogo para a equipe, essenciais para uma boa competição.

Outro ponto identificado na análise é a produção e reprodução de um discurso de ansiedade e expectativa nas matérias. $\mathrm{Na}$ mesma inserção referida acima, a repórter pergunta a Cristiane, em tom descontraído, sobre uma possível tatuagem com motivo olímpico, quando a atleta responde: "só quando ganhar a medalha". Imediatamente, a apresentadora Fernanda Gentil rebate dizendo estar na torcida para que essa ideia se concretize no mesmo

1 É importante ressaltar que ela foi a repórter responsável pela maioria das matérias usadas para análise neste estudo. 
ano. Observa-se, então, que há um reforço e potencialização da espera pela medalha de ouro quando a mídia repercute esse clima ansioso existente entre as próprias jogadoras.

Em um distinto momento do caminho trilhado até o ouro, o tom é de fracasso. Apesar de não ser explícita a intenção e mesmo que o apoio da torcida jamais visto e sentido da forma com que aconteceu já tenha sido uma grande conquista (aspecto que será abordado mais a frente), as menções à seleção assumem um tom de relativa frustração pela falha no objetivo vendido e reproduzido durante toda a competição, o ouro, terminando em um amargo e incompreensível quarto lugar, após uma primeira fase impecável e bem superior à masculina (ponto que também será aprofundado mais à frente).

É latente a percepção que o tratamento conferido às jogadoras de futebol pela mídia nessa categoria se atém ao futebol em si, ao fato de elas serem atletas profissionais e de estarem em uma Olimpíada para competir e em busca da vitória como qualquer outro atleta, sem o evidente (e clássico) reforço ou foco em estereótipos que tirem o centro do esporte enquanto atividade profissional.

Como Birolli (2011) afirmou, a mídia tem o poder de atuar sob uma perspectiva que vá de encontro à manutenção de concepções engessadas, apresentando as realidades diversificadas, que passam a fazer parte da vivência e da realidade de cada indivíduo. E nesse caso, há uma tentativa de naturalização para posterior aceitação da imagem da mulher-atleta, que conquistou e consolidou seu espaço no esporte perante a sociedade.

\subsection{Marta: a consolidação de um ídolo}

O homem e a mulher sempre tiveram a necessidade de representar e se sentir representados desde o surgimento da humanidade. Isso porque as representações se constituem como um ponto seguro de identificação (Hall, 2016). O ato de se sentir representado, de se familiarizar com símbolos, práticas e expressões são pontos fundamentais e imprescindíveis na formação e construção de identidades.

Quando essas representações, entretanto, ganham o status de estereótipos, elas geram o efeito contrário: um sentimento de negação, de exclusão, de repulsa. Bhabha (1998) cita Fanon para exemplificar uma das consequências do estereótipo. Uma criança negra, mas que com toda a carga social de pejorativismos, preconceitos e concepções normativas, rejeita a própria identidade negra. Como exposto anteriormente, os estereótipos atuam preferencialmente onde há desequilíbrio simbólico de poder (Hall, 2016).

Nesse jogo de representar e eleger modelos de identificação, a mídia se reveste de uma importância sem igual nas sociedades pós-modernas. Birolli (2011) explica que a relação contemporânea é

mediada por imagens produzidas e difundidas em escala industrial, fazendo com que nossas referências sejam uma fusão entre o mundo com o qual temos contato diretamente 
e o mundo que conhecemos pelas telas da TV, pela internet e pelas páginas de revistas e jornais (p. 85).

No caso do esporte, que hoje se configura como uma atividade profissional e extremamente lucrativa, a mídia acaba por eleger figuras representativas, cuja importância não se atém somente aos resultados potenciais, mas ultrapassa as esferas esportivas. Em se tratando de Brasil, os ícones esportivos se encontram em sua maioria no futebol e não necessitam da participação em uma edição dos Jogos Olímpicos e, principalmente, vitória para se consolidarem como tais.

A citar Pelé, considerado o melhor jogador da história do futebol e um dos grandes responsáveis por alavancar o esporte brasileiro no cenário internacional e torná-lo a grande referência para as outras nações, nunca ganhou um torneio olímpico, mas se consagrou tricampeão mundial e ainda assim é um ídolo que atravessa gerações.

De modo semelhante ao Pelé, há Marta Vieira da Silva, ou apenas Marta. Camisa 10 da seleção feminina, principal jogadora da atual composição do time (e arrisca-se dizer da história da canarinha), a alagoana de origem humilde carrega o status de ídolo para uma geração de amantes do futebol e de garotas que um dia sonham ser como a futebolista. É por isso que a atleta de habilidades inquestionáveis possui uma categoria só para si.

A mídia e, especificamente, neste estudo, os programas trazem a imagem e a fala de Marta como um fator de familiarização e identificação. Nos vídeos identificados na categoria Marta: a consolidação de um ídolo, há um recorrente uso de Marta para legitimar e conferir ainda mais credibilidade ao que se apresentava no conteúdo das matérias e aproximar o telespectador do futebol feminino, constantemente invisibilizado no contexto midiático e cuja realidade é praticamente desconhecida do público geral.

Pioneira, transgressora, a craque tem contribuído intensamente para modificar a realidade das mulheres no futebol no Brasil, tanto no que diz respeito à imagem e representações quanto no que se refere ao incentivo e políticas públicas para o desenvolvimento do esporte. Assim, a atacante canhota se transformou em referência sólida e modelo supremo de atleta e mulher. Dessa forma, o principal nome da seleção é constantemente solicitado nas matérias para produzir essa sensação de segurança, respeito, carinho e admiração pela equipe que disputou as Olimpíadas.

Nessa categoria, as matérias nela enquadradas produzem e repercutem o grande nome do futebol feminino no país sob três vieses representativos. Essas representações criam três pontos distintos de identificação acerca de uma mesma identidade: a de Marta enquanto atleta e craque e, portanto, ídolo de uma geração; a de porta-voz, de legitimadora e fator de reconhecimento entre o público; e a de ídolo comum, ser humano e mulher acima de qualquer coisa, que falha, que ri, que chora, que é gente como qualquer outra pessoa. Assim, se confirma a ideia tão aclamada de identidade plural, diversa, cuja cada uma se sobressai em momentos e locais distintos a depender do que o contexto demanda (Woodward, 2000). 
Na matéria intitulada "Seleção Brasileira de Futebol Feminino vence o último amistoso antes da Olimpíada" ("Esporte Espetacular", 24/VII/2016), a apresentadora Glenda Kozlowski, ao chamar o vídeo, destaca que a craque Marta foi o nome do jogo ao afirmar que "foi dia de Marta". No corpo da matéria, a repórter Maíra Lemos reitera essa informação. Coberta pela imagem de um drible da camisa 10, o texto ressalta que "Marta estava inspirada".

Com o passar da competição, Marta foi sendo adotada cada vez mais pelo brasileiro. Tal fenômeno é sutilmente apresentado na matéria "Já classificada, seleção brasileira feminina de futebol empata sem gols com a África do Sul na Olimpíada" ("Globo Esporte", 10/ VIII/2016). No último jogo da fase classificatória para o mata-mata, realizado em Manaus (AM), Marta iniciou a partida na reserva. A repórter Maíra Lemos logo ressalta que "Marta, no banco, era ovacionada". Em seguida, entram imagens da torcida entoando o popular "Marta, cadê você? Eu vim aqui só pra te ver". No mesmo vídeo, a jornalista ainda destaca que a cada vez que a futebolista chegava perto da bola, a torcida ficava eufórica. O discurso midiático serve para reforçar a idolatria a Marta e reproduz o gigantismo da atleta, que ultrapassa as quatro linhas.

Em um número significativo de matérias, Marta é solicitada para confirmar informações, dar opiniões sobre a preparação, os treinos e a postura dentro de campo. Por toda a carreira e significado que a alagoana possui, ela detém esse poder de legitimação frente ao público, que a usa como imagem de aproximação e conforto. E mais do que legitimar, Marta assume o papel de líder do grupo, chamando para si as responsabilidades sobre toda a equipe, formada, primordialmente, por atletas jovens, que jogariam a primeira Olimpíada.

Além das imagens de ídolo-craque e ídolo-líder, Marta é representada sob a ótica do ídolocomum, humanizado. Intitulada "Marta, da seleção feminina, fala do último teste antes das Olimpíadas" ("Globo Esporte”, 23/VII/2016), a matéria mostra logo no início outra Marta. A jogadora sempre responsável e sob a imagem e aura de liderança se diverte ao cantar e dançar um samba (ritmo intrinsecamente associado ao futebol), mesmo sentada. Em um clima de descontração, a atacante até pega um microfone para interpretar. Ainda no mesmo vídeo, a repórter Maíra Lemos pergunta o que fazer para acabar com ansiedade da estreia nos Jogos, pressupondo e reforçando a ideia de que Marta, como uma pessoa comum, também sente nervosismo, pressão. A jogadora, então, responde que usa a música para aliviar a tensão.

É passível observar que o jornalismo esportivo sob análise nesta pesquisa privilegia os aspectos técnicos em detrimento de se preocupar com questões a parte do esporte e que envolvem, primordialmente, os estereótipos que reduzem a identidade feminina a uma série de padrões e normas sociais que devem ser obedecidas sob a pena de exclusão moral. Se, como Goellner (2005a) explicitou, a mídia constantemente tratava as mulheres futebolistas sob a ótica de uma masculinização inevitável, com questionamentos dúbios acerca da sexualidade das atletas, nas matérias aqui analisadas, não se faz qualquer referência a pontos que não digam respeito ao futebol. 
Pelo contrário, ao mostrar e exaltar Marta e suas grandes conquistas, cria-se diferentes possibilidades de identificação. Seja com o ídolo, que é um ser humano comum, seja com a mulher, craque, que fez e faz história em um ambiente considerado majoritariamente masculino, quebrando barreiras, destruindo preconceitos e mostrando que a mulher pode e deve jogar futebol ou qualquer outro esporte e ocupar qualquer espaço, desde que essa sua vontade.

\subsection{Nova geração $x$ craques do passado: renovação e desconhecimento}

Não é possível precisar uma data exata para o início da profissionalização do esporte. Mas, como Rubio (2010) aponta, foi nos Jogos Olímpicos de Barcelona, em 1992, que se visualizou a magnitude de uma equipe esportiva, cujas atitudes repercutiam muito mais fora das competições esportivas, pela primeira vez. É nesse contexto de profissionalização da atividade esportiva que os esportistas buscam e prezam por uma especialização cada vez mais intensa, específica, que seja garantia de resultados inimagináveis.

No futebol, essa realidade não seria diferente. A luta para ingressar no mundo futebolístico de alto nível começa muito cedo para homens e mulheres, o que encurta ainda mais as carreiras, especialmente devido ao desgaste corporal. Para o futebol masculino, essa constante renovação de elencos é natural e até incentivada. No caso do futebol feminino, pesa a falta de incentivo e políticas públicas à prática, além da constante invisibilidade a que são submetidas pela mídia. Segundo Goellner (2005a), “a mídia esportiva pouco confere espaço ao futebol feminino" (p. 150).

Quando acontece alguma renovação de elenco na Seleção Feminina, boa parte dos nomes é totalmente desconhecida do público. Além de relegadas a um plano secundário pela mídia, a maioria dessas meninas se divide entre a dura realidade dos clubes de várzeas e campeonatos praticamente amadores (Goellner 2005a) ou a profissionalização no exterior, ocupando um espaço ainda menor na mídia.

Desse modo, é a dicotomia entre a experiência das grandes craques, reconhecidas e familiares a um público mais leigo, e a necessidade de renovação, com o frescor de uma nova geração, porém sem qualquer tipo de reconhecimento da torcida, evidenciada na categoria "Nova geração x craques do passado: renovação e desconhecimento". Nos vídeos aqui expostos, há uma tentativa constante de traçar um paralelo entre esses dois grupos, como forma de confirmar a importância da experiência e de propagar ações afirmativas ao recebimento das mais jovens do grupo.

Um ponto verificado nesta análise e que merece destaque é que o teor da abordagem acerca das novas caras da seleção confirma, implicitamente, a "falha" ou postura adotada pela mídia de eleger outros assuntos em detrimento de colocar o futebol feminino em um lugar secundário. Uma das características observadas nessas matérias foi a atitude de apresentar, as atletas mais jovens para familiarizar e acostumar o público àqueles rostos. 
O caminho adotado pelos programas aqui analisados de introduzir a imagem das novas atletas e criar no imaginário social a legitimação dessas meninas como o futuro da seleção e substitutas das craques que marcaram uma geração vitoriosa e transgressora do futebol feminino brasileiro é percebido apenas nas matérias veiculadas antes da estreia nos Jogos. Como no VT, intitulado "Andressa Alves é o novo reforço do Barcelona e vai conhecer Messi, Suárez e Neymar” (“Globo Esporte”, 28/VII/2016).

A atacante Andressa é, de acordo com a repórter Maíra Lemos, "uma jogadora que todo mundo quer: jovem, 23 anos de idade e polivalente". Durante a preparação para os Jogos, a atleta fechou contrato para defender a equipe do Barcelona, clube espanhol e um dos mais vitoriosos do século. De feições semelhantes a Marta, inclusive usando o mesmo penteado (um rabo de cavalo), a futebolista é apresentada, sutilmente, como uma possível sucessora a ocupar o lugar de craque dessa geração que está por vir e está tentando se consolidar. Ao enfatizar que a jogadora possui "muita qualidade" com a bola nos pés, a repórter produz uma sensação de segurança e confiança no torcedor quanto ao talento e qualidades técnicas do grupo que está se formando.

Por outro lado, as matérias analisadas também procuraram exaltar a experiência e o talento das atletas que já fizeram história com a camisa da seleção, representadas sob a figura de Cristiane, de Formiga e Marta, ponto aprofundado na categoria anterior. Por isso, nessa categoria, craques do passado é uma referência a Cristiane e Formiga.

Na matéria "Seleção feminina de futebol vence a China na estreia da Olimpíada 2016" ("Globo Esporte", 4/VIII/2016), a repórter Maíra Lemos, ao comentar sobre o gol de Cristiane, enfatiza mais uma vez "Cristiane, a maior artilheira do futebol feminino em Olímpiadas. 13 gols”. Nesse sentido, a repórter gera o sentimento de conforto e alívio no torcedor, já que a equipe brasileira possui a maior marcadora de gols da história dos Jogos. Fato esse confirmado na fala da própria atleta na mesma matéria, ao afirmar que os torcedores "contam muito com isso e a torcida espera isso sempre da gente", isto é, naturaliza-se o discurso de que a experiência é resolutiva e se faz presente nos momentos necessários.

Do mesmo modo, a marca histórica da atacante Formiga também é exaltada. No dia da estreia nos Jogos, na cabeça da matéria, intitulada "Seleção feminina de futebol estreia nos Jogos Olímpicos nesta quarta contra a China" ("Globo Esporte”, 3/VIII/2016), a apresentadora Fernanda Gentil, posicionada ao lado de um holograma de Formiga fazendo embaixadinhas, destaca "Formiga, muita habilidade na embaixadinha, vem para a sexta olimpíada dela". Desde a inserção do torneio feminino de futebol nas Olimpíadas, na edição de 1996, em Atlanta, a jogadora esteve em todos os Jogos. Ressalta-se, portanto, a importância da experiência em competições dessa magnitude.

Desse modo, a mídia demonstra que estar no futebol feminino, realizar o sonho de representar o país de origem na maior competição esportiva do mundo e construir uma carreira sólida e vitoriosa (ao que pese as enormes dificuldades) são realidades possíveis e palpáveis. Além disso, ao mostrar essas meninas, ressaltando as qualidades, o talento, os 
feitos históricos, sem o peso das concepções estereotipadas, a mídia cria um discurso de incentivo à inserção da mulher no futebol, que se relegou durante muito tempo a esconder suas vontades com receio das insígnias provenientes do tabu "mulher praticando futebol".

Portanto, evidencia-se o quão fundamental a mídia se constitui na produção dos sentidos sociais que serão adotados pela sociedade, especialmente porque "sua força consiste no caráter persuasivo em dar visualidade aos acontecimentos e às interpretações” (Morigi, 2004, p. 7) E é por isso que ela é detentora da capacidade e possibilidade de permitir o acesso a realidades distintas, gerando aceitação e novas formas de representação e identificação.

\subsection{A paixão de uma torcida}

Falar em Brasil é falar em futebol, a grande paixão nacional, aqui com a ressalva das exceções. O certo é que a prática futebolística se configura como um dos símbolos constituintes da identidade cultural brasileira. Segundo Freyre, citado por Stein (2015), esse esporte se transformou em uma instituição de domínio brasileiro. Para o autor, o esporte bretão se tornou tão popular em um país tão distante e diferente da Inglaterra pelo poder unificador de uma sociedade praticamente estratificada em uma época crítica da história brasileira.

Entretanto, se por um lado o futebol se consolidava como elemento representativo da cultura brasileira e sua prática era incentivada entre os homens, por outro, as mulheres que, por ventura, quisessem se inserir nesse meio sofriam com constantes medidas proibitivas, com olhares de desconfiança e preconceito e com representações normativas, que as consideravam desviantes de uma identidade feminina imaginada e reproduzida por um discurso hegemônico (Goellner, 2005b).

Com a ajuda do reforço midiático na construção de sentidos que inferiorizavam as mulheres e as colocavam envoltas de estigmas paralisadores, o futebol feminino era, nos primórdios do seu desenvolvimento, "um divertimento para os outros, a inabilidade fazia com que o jogo fosse visto como uma caricatura, com tons de comédia, misto de curiosidade e frenesi” (Mourão \& Morel, 2005, p. 76).

O que se percebe na categoria "A paixão de uma torcida", entretanto, é um movimento contrário ao que se acontecia no início do século passado. Incentivados pelas subsequentes vitórias, uma campanha arrebatadora na primeira fase somada a inicial decepção com a seleção masculina (sob quem se tinha depositado grande expectativa, especialmente após a troca de técnico) e boas atuações, com um futebol de "encher os olhos" e que não deixava a desejar em relação ao masculino, os brasileiros foram, gradativamente, enchendo cada vez mais os estádios, apoiando as atletas incondicionalmente e adotando o discurso da mídia de reconhecimento, apoio e orgulho.

As matérias trouxeram, constantemente, a importância da torcida como incentivo para as partidas, reforçado pela fala das atletas. Se o que se verificava antes era a desconfiança, 
o deboche, a ridicularização e a estereotipagem, nas Olimpíadas do Rio, os brasileiros adotaram a seleção feminina como jamais tinha se visto antes e a acompanharam em um movimento de apoio, alegria e satisfação até o último momento. E mesmo que o resultado esperado não tenha sido alcançado, a torcida reconheceu o valor, a luta, o esforço e a dedicação daquelas atletas, que enfrentam muitas dificuldades para poder concretizar o sonho de viver "do" e para o futebol.

Acompanhando essa onda de apoio maciço e credibilidade vinda das arquibancadas e de uma parte significativa dos brasileiros, os programas em questão passam a influenciar ainda mais a participação da torcida, convocando-a para as partidas. Na primeira matéria, já falada anteriormente ("Globo Esporte", 24/VII/2016), é importante ressaltar as imagens de carinho, euforia, animação e alegria da torcida presente com as jogadoras, mesmo que a maioria delas fosse desconhecida. Nesse momento, se destaca a imagem de uma torcedora segurando um papel com os dizeres "Eu acredito! Já comprei a final!", antecipando esse apoio incondicional que contagiaria o Brasil durante o período olímpico.

Antes estigmatizadas por um discurso social paralisador e estereotipado sob influência das representações difundidas pela mídia de uma identidade feminina que deveria ocupar apenas o ambiente doméstico, de inferioridade e incapacidade, às jogadoras de futebol é atribuído, agora, credibilidade e confiança no que diz respeito às qualidades técnicas e às possibilidades de conquista.

Mas é em outro momento do torneio olímpico que o apoio à seleção feminina se mostra decisivo. Nas quartas-de-final, que valia a classificação para as semifinais, a vitória só veio na cobrança de pênaltis e, segundo Marta (que teve a sua cobrança defendida), na matéria intitulada "Diante de maior público na Olimpíada, Bárbara salva e Brasil chega nas semifinais" ("Globo Esporte", 13/VIII/2016), os torcedores "foram com a gente até o fim", sendo fundamentais para essa classificação.

Em uma matéria, intitulada "Mesmo sem medalha na Olimpíada, torcida apoia e exalta seleção brasileira feminina de futebol" ("Globo Esporte", 20/VIII/2016), o repórter e as jogadoras reforçam essa onda de apoio à seleção. Em sua passagem, o repórter ressalta que "o prêmio vem das arquibancadas: o reconhecimento da torcida". Torcida que aplaudiu a equipe ao fim da partida mesmo com a derrota. Na mesma matéria, a atacante Debinha confirma: "O maior legado que a gente teve foi o carinho da torcida e ver esse reconhecimento de todos, pra gente, não tem explicação".

É válido ressaltar que ainda devem existir falas que reproduzam comentários machistas, estereotipados e pejorativos acerca das mulheres que jogam futebol, mas, nesse caso, o que se viu foi a substituição deste por um discurso de valorização e reconhecimento do bom futebol apresentado pela seleção, inclusive pelos programas analisados, que não focaram a representação das meninas na derrota, na "falha", mas nas conquistas: maior espaço e valor ao futebol feminino no Brasil. 


\subsection{Natureza feminina: a alteridade do masculino}

Em seu estudo sobre a construção da identidade feminina entre as vítimas da Guerra de Canudos, Oliveira (2002) é enfático ao demonstrar que, àquela época, o homem e a mulher foram pontos identitários um do outro. Nesse sentido, como exposto no capítulo sobre as discussões em torno da identidade, esta acontece e é constituída em relação a um "Outro" no contexto das interações sociais (Woodward, 2000).

O binarismo na constituição e estabelecimento de identidades, entretanto, as reduz a representações sociais normativas, padronizadas, estigmatizadas e exclusivas. Na relação mulher x homem, a primeira está ligada à emoção, à inferioridade, dependência, fragilidade, enquanto o segundo é associado à razão, à superioridade e domínio, independência, força.

Nos esportes, essa realidade não se mostra diferente. O gênero era usado como justificativa para a divisão de modalidades esportivas (Goellner, 2010). As construções acerca do que se define como um esporte masculino e uma atividade feminina ainda é bastante presente no imaginário social já que nos primórdios do desenvolvimento dos esportes no Brasil havia essa clara divisão entre o que seria adequado para os homens (a agressividade) e para as mulheres (a leveza, graciosidade, suavidade a fim de não masculinizar o corpo feminino, modelo de feminilidade) (Goellner, 2008).

Se até o momento a análise demonstrou que as matérias não se ativeram às questões estereotipadas acerca das representações da mulher na mídia e sim as diversificaram e apresentaram outras formas de representar e outras possibilidades de identificação, é nessa categoria que é possível perceber que "há posições e imagens conflitantes sendo difundidas pelos meios de comunicação simultaneamente" (Birolli, 2011, p. 88). Além disso, os vídeos aqui enquadrados evocam, mesmo que sutilmente e em menor grau, alguns dos estereótipos que engessam a identidade feminina em torno de concepções padronizadas.

Em alguns momentos, os textos das matérias trazem à luz imagens estereotipadas secularmente associadas ao mundo feminino, contribuindo para reforçar algumas ideias acerca da identidade feminina já presentes e solidificadas no imaginário social e da própria mídia, que sempre usa imagens típicas para personificar um conteúdo, facilitando a rotina produtiva jornalística e a compreensão do público, que já se sente familiarizado com determinadas representações (Birolli, 2011). Apresentar uma mulher, atleta, jogadora de futebol com características que correspondam às expectativas sociais sobre o ser mulher é um caminho relativamente mais fácil do que assumir que as identidades são plurais e diversas.

Na matéria "Seleção de futebol feminino terá decisão contra a Austrália no Mineirão" ("Globo Esporte", 12/VIII/2016), a repórter Maíra Lemos associa a expressão "coração de mãe" às jogadoras, naturalizando e reforçando o clássico discurso de que a mulher nasce para a maternidade e que as condutas femininas são pautadas pelas emoções, pelo sentimentalismo, simbolizados pelo coração. Ou seja, tornam o senso comum de que "mulher é coração" uma verdade inquestionável. Reitera-se, então, a mídia como 
propagadora de representações homogêneas, que são consideradas a realidade na sua totalidade (Birolli, 2011).

Essa suposta natureza feminina intrinsecamente ligada a um turbilhão de emoções e à sensibilidade é reforçada na matéria intitulada "Mesmo sem medalha na Olimpíada, torcida apoia e exalta seleção brasileira feminina de futebol" ("Globo Esporte", 20/VIII/2016). O repórter ressalta "a nossa camisa 10 não aguentou e foi às lágrimas", enfatizando que o ato de chorar de Marta seria uma atitude inevitável e uma reação natural tendo em vista o resultado conquistado. Ao usar a expressão "não aguentou", o jornalista naturaliza e reforça a ideia de que as mulheres possuem as emoções à flor da pele e são naturalmente emotivas.

Nesse processo de normatização da identidade feminina, é constante o uso da imagem masculina como ponto de alteridade para a constituição identitária da mulher, além de comparar exaustivamente o futebol feminino ao masculino, como se o primeiro "não tivesse vez na cultura esportiva brasileira" (Mourão \& Morel, 2005, p. 84).

Em um momento, na matéria intitulada "Seleção feminina de futebol vence a China na estreia da Olimpíada 2016” (“Globo Esporte”, 4/VIII/2016), mais uma vez Neymar é evocado para transmitir essa sensação de segurança tanto para as jogadoras quanto para o torcedor. A matéria traz um vídeo retirado da internet, em que Neymar e outros atletas desejam sorte para as meninas na estreia. Ao se observar todo o conteúdo do VT, é possível verificar que o recado de Neymar e companhia é acessório para a composição final do sentido da matéria. Ou seja, o seu uso pode ser justificado pela constante ativação pela mídia de concepções engessadas, que promovem atores sociais em detrimento de outros (Birolli, 2011).

\subsection{Show de futebol}

Na caracterização da identidade brasileira, o futebol, certamente, se configura como um dos principais aspectos constituintes. Mas como e por que o futebol aqui jogado é tão diferente e aclamado? A arte nos pés seria influência direta da miscigenação que constitui a sociedade brasileira, especialmente com a presença dos negros nessa mistura (Freyre, citado por Barreto, 2004).

Freyre defende que a diferença e a genialidade do futebol-arte brasileiro residem na dança, que permite improvisos, criatividade, espontaneidade e astúcia (Barreto, 2004). A destreza, rapidez, a magia, o jogo envolvente, os passes geniais, os dribles inacreditáveis, a dança com a bola seria, então, o que permite considerar a prática futebolística no Brasil como arte.

Entretanto, o domínio dessa arte, apesar de característico da identidade cultural brasileira, estaria restrito aos homens. Isto é, além de não estarem socialmente permitidas (e, posteriormente, sob o âmbito legal) a jogar futebol, as mulheres não teriam a capacidade e habilidade necessárias para tal. 
Hall (2016) explica que os estereótipos funcionam em dois níveis, um evidente e o ouro reprimido. O primeiro pode ser um disfarce para um segundo. A estereotipagem determinada pelos homens acerca da inabilidade esportiva das mulheres, em especial o futebol, pode disfarçar um medo latente de que estas fossem melhores que eles.

Se nos primórdios, o futebol feminino era representado sob a insígnia de deboche, de incapacidade, de espetáculo dos horrores, o que se percebe nessa categoria "Show de futebol" é a legitimação das jogadoras pela técnica e habilidade. Nas matérias enquadradas nessa categoria, portanto, evidencia-se a qualidade técnica do futebol feminino, em referência ao futebol-arte, ao estilo de jogar do brasileiro. Abandonam-se as concepções estereotipadas que naturalizam a condição feminina secular para substituí-las por diversificadas e plurais representações, que apresentam a identidade da mulher atleta, com o uso constante de termos como "dribles", "passes", "show", "festa", "talento", "habilidade", entre outros.

Diferente do que expôs Goellner (2005a), de que a mídia "menciona não tanto os talentos esportivos das atletas, árbitras e treinadoras, mas a sua imagem e o seu comportamento" (Goellner, 2005a p. 150), o foco da abordagem dos programas analisados durante a cobertura olímpica é o futebol, enquanto prática esportiva, que exige técnica, treino, talento, habilidade e preparo.

Em uma matéria sobre o último amistoso da seleção contra a Austrália antes da estreia nos Jogos, com o título "Seleção Brasileira de Futebol Feminino vence último amistoso antes da Olimpíada" ("Esporte Espetacular", 24/VII/2016), ao começar a falar sobre a partida, a repórter Maíra Lemos logo destaca que "Cristiane deu um show de dribles e passes. E Marta também estava inspirada". Por meio dessa fala, é possível apreender a tentativa de naturalizar e provocar a aceitação quanto à habilidade feminina para o futebol.

O talento das atletas individualmente também é exaltado, como na matéria intitulada "Andressa Alves é o novo reforço do Barcelona e vai conhecer Messi, Suárez e Neymar" ("Globo Esporte", 28/VII/2016). A repórter Maíra Lemos destaca a polivalência da atleta, que pode atuar como lateral-esquerda, volante, meia-atacante e atacante, demonstrando as habilidades da jogadora e enfatizando que "é muita qualidade". Assim, Andressa é representada de acordo com seus atributos técnicos, rompendo com os estereótipos de estética, sexualidade e feminilidade sob os quais essas atletas eram (e ainda são) constantemente pautadas.

Outro aspecto verificado é acerca do teor da abordagem adotado para a produção do conteúdo relacionado aos jogos. Evidenciando a especialização necessária para o jornalismo esportivo, as matérias retratam os aspectos técnicos, como as finalizações, o posicionamento, o esquema tático, as jogadas, os passes, enfim, caracterizações comuns de uma partida de futebol, que refletem a preocupação desses programas em desmitificar o ideário que mulher não sabe jogar futebol. Além de representar essas jogadoras sob a perspectiva de uma identidade que não é normativa das concepções sociais acerca do ideário de ser mulher. 


\section{Considerações finais}

A partir do questionamento acerca de como é construída a identidade feminina da atleta, jogadora de futebol nos noticiários esportivos e como é essa identidade, o resultado da análise permitiu compreender como essas mulheres são representadas partindo das narrativas construídas nas matérias analisadas.

Ao contrário do que era esperado, os programas aqui analisados rompem com as barreiras estereotipadas secularmente construídas em torno de uma identidade feminina imaginada, carregada de concepções engessadas e representações normativas, que excluem quem não as cumpre. Em um movimento de naturalização, as matérias evidenciam outras formas de representações, criando e diversificando-as, colocando o telespectador em contato com outras realidades e outras maneiras de compreendê-las e interpretá-las.

De uma maneira geral, a maioria das categorias encontradas foca, como assim dever ser, no futebol e nas identidades que aquelas mulheres estão ali assumindo: a de atletas profissionais, jogadoras de futebol, além de criar e reproduzir um discurso que aceita a diversidade de possibilidades, a pluralidade de identificações. A mulher pode ser mãe, como também pode jogar futebol. Uma identidade não deve excluir a outra.

É importante destacar, entretanto, que apesar das tentativas de naturalização e aceitação por meio de representações diversificadas e plurais das mulheres, ainda há uma referência e a evocação de convenções sociais para identificar o gênero feminino. Na categoria "Natureza feminina: a alteridade do masculino", as imagens difundidas reforçam os tipos femininos construídos em oposição binária, sob a influência de uma relação desigual de poder, ao homem.

Assim, o lócus social que as jogadoras de futebol ocupam ainda se configura como ambíguo, convergindo com as ideias de Goellner (2005a, 2005b). Ora apresentadas na forma das clássicas representações, ora sendo espaço de diversidade e pluralidade, aceitando as discussões acerca de identidades plurais e diversas. O que não pode deixar de ser ressaltado é a atuação dos programas analisados nesta pesquisa, que, na contramão da mídia tradicional, diversifica a identidade feminina e quebra os laços com a manutenção dos estereótipos associados a uma suposta natureza da mulher. Nesse caso, a mídia atua sob a perspectiva de ruptura com as imagens convencionais, as representações engessadas, reproduzindo e gerando aceitação de outras formas de compreender e interpretar o mundo.

\section{Referências}

Bardin, L. (2011). Análise de conteúdo. Lisboa: Edições 70.

Barreto, T. (2004). Gilberto Freyre e o futebol-arte. Revista USP, 62. Recuperado de http://www.periodicos.usp.br/revusp/article/download/13357/15175 
Bastos, A. \& Ristum, M. (2003). A violência urbana e o papel da mídia na concepção de professoras do ensino fundamental. Paidéia, 13(26), 181-189.

Bhabha, H. (1998). O Local da Cultura. Belo Horizonte: Editora UFMG.

Birolli, F. (2011). Mídia, tipificação e exercícios de poder: a reprodução dos estereótipos no discurso jornalístico. Revista Brasileira de Ciência Política, 6, 71-98.

Boris, G. \& Cesídio, M. (2007). Mulher, corpo e subjetividade: uma análise desde o patriarcado à contemporaneidade. Revista Mal-Estar e Subjetividade, 7(2). Recuperado de http://www.redalyc.org/articulo.oa?id=27170212

Carvalho, M. (2011). O conceito de gênero: uma leitura com base nos trabalhos do GT Sociologia da Educação da ANPEd (1999-2009). Revista Brasileira de Educação, 16(46). Recuperado de http://www.scielo.br/scielo.php?pid=S141324782011000100006\&script=sci_abstract\&tlng=pt

Castro, A. \& Prado, J. (2004). Corpo e Identidades Femininas: a intermediação da mídia. Estudos de Sociologia, 17(32), 241-259.

Escosteguy, A. (2001). Cartografia dos estudos culturais: uma versão latino-americana. Belo Horizonte: Ed. Autêntica.

Goellner, S. (2005a). Mulheres e futebol no Brasil: entre sombras e visibilidades. Revista Brasileira de Educação Física e Esporte, 19(2). Recuperado de http://www. revistas.usp.br/rbefe/article/view/16590

Goellner, S. (2005b). Mulher e esporte no Brasil: entre incentivos e interdições elas fazem história. Pensar a prática, 8(1). Recuperado de https://www.revistas.ufg.br/fef/ article/view/106

Goellner, S. (2008). "As mulheres fortes são aquelas que fazem uma raça forte": esporte, eugenia e nacionalismo no Brasil no início do século XX. Recorde: Revista de história do esporte, 1(1). Recuperado de https://revistas.ufrj.br/index.php/ Recorde/article/view/790

Goellner, S. (2010). A educação dos corpos, dos gêneros e das sexualidades e o reconhecimento da diversidade. Cadernos de Formação RBCE, 1(2). Recuperado de http://revista.cbce.org.br/index.php/cadernos/article/view/984

Hall, S. (2000). A identidade cultural na pós-modernidade. Río de Janeiro: DP\&A.

Hall, S. (2016). Cultura e Representação. Río de Janeiro: Editora PUC-Rio, Apicuri. 
Morigi, V. (2004). Teoria Social e Comunicação: Representações sociais, produção de sentidos e construção dos imaginários midiáticos. E-Compós: Revista da Associação Nacional dos Programas de Pós-Graduação em Comunicação, 1(1). Recuperado de http://www.e-compos.org.br/e-compos/article/view/9

Moscovici, S. (2015). Representações Sociais: Investigações em psicologia social. Petrópolis: Editora Vozes.

Mourão, L. \& Morel, M. (2005). As narrativas sobre o futebol feminino - O discurso da mídia impressa em campo. Revista Brasileira de Ciências do Esporte, 26(2). Recuperado de http://revista.cbce.org.br/index.php/RBCE/article/view/148

Oliveira, W. (2002). Entre Bruxas e Princesas: A construção de identidades femininas entre as prisioneiras de Canudos. En A. Costa \& C. Sardenberg (Orgs.). Feminismo, ciência e tecnologia (pp. 305- 318). Salvador: REDOR/ NEIM-FFCH/ UFBA.

Pollak, M. (1992). Memória e Identidade Social. Estudos históricos, 5(10), 200-212.

Proni, M. (2009). Observações sobre os impactos econômicos esperados dos Jogos Olímpicos 2016. Motrivivência, 21(32-33). Recuperado de https://periodicos. ufsc.br/index.php/motrivivencia/article/view/2175-8042.2009n32-33p49

Rubio, K. (2010). Jogos Olímpicos da Era Moderna: uma proposta de modernização. Revista Brasileira de Educação Física e Esporte, 24(1). Recuperado de http:// www.scielo.br/pdf/rbefe/v24n1/v24n1a06.pdf

Scott, J. (1995). Gênero: uma categoria útil de análise histórica. Educação \& Realidade, 20(2), 71-99.

Silva, T. (Org.), Hall, S. \& Woodward, K. (2000). Identidade e diferença: A perspectiva dos Estudos Culturais. Petrópolis: Vozes.

Stein, L. (15 de abril de 2015). Como o futebol moldou a identidade cultural do brasileiro. Recuperado de https://trivela.com.br/como-o-futebol-moldou-a-identidadecultural-do-brasileiro/

Woodward, K. (2000). Identidade e diferença: uma introdução teórica e conceitual. En T. Silva (Org.), S. Hall \& K. Woodward, Identidade e diferença: A perspectiva dos estudos culturais (pp. 7-72). Petrópolis: Vozes. 